\title{
PENGEMBANGAN POTENSI USAHA HASIL TERNAK BERBASIS POPULASI DAN KELEMBAGAAN DI PROVINSI JAWA BARAT
}

\author{
Iman Trisman**1, M. Munandar Sulaeman ${ }^{1}$, Marina Sulistyati ${ }^{2}$ \\ ${ }^{1}$ Program Pascasarjana Fakultas Peternakan, Universitas Padjadjaran \\ Jl. Raya Bandung Sumedang Km 21, Jatinangor Sumedang \\ ${ }^{2}$ Departemen Sosial Ekonomi Pembangunan Peternakan, Fakultas Peternakan, \\ Universitas Padjadjaran Jl. Raya Bandung Sumedang Km 21, Jatinangor Sumedang, \\ *Email: mansdonk@gmail.com
}

(Diterima 06-01-2022; Disetujui 27-01-2022)

\begin{abstract}
ABSTRAK
Tujuan dari penelitian ini adalah mengkaji/menganilisis pengembangan potensi usaha hasil ternak berbasis populasi dan kelembagaan usaha ternak. Penelitian dilakukan dengan metode gabungan (mixed method), yaitu metode kuantitatif dan kualitatif. Metode kuantitatif digunakan untuk mengetahui komoditas basis berdasarkan variabel populasi dan kelembagaan, kemudian metode kualitatif digunakan untuk menganalisis pengembangan potensi usaha hasil ternak. Hasil penelitian menunjukkan bahwa ada tujuh kabupaten/kota yang memiliki potensi pengembangan usaha komoditas sapi potong yaitu Kabupaten Indramayu, Kuningan, Pangandaran, Subang, Kota Tasikmalaya, Sumedang, dan Majalengka. Sedangkan komoditas sapi perah berpotensi dikembangkan di enam wilayah kabupaten/kota yaitu Bandung Barat, Kota Cimahi, Bandung, Bogor, Kuningan, dan Subang. Harapannya ke depan pengembangan usaha hasil peternakan komoditas sapi potong dan sapi perah bisa dikembangkan di wilayah-wilayah tersebut melalui pemberdayaan kelompok ternak dengan memanfaatkan sumber daya daya lokal.
\end{abstract}

Kata kunci: Komoditas Basis, UPH, Kelembagaan Peternak

\section{ABSTRACT}

The research was aimed to investigate business of development of livestock product based on animal population and institutional business. The research was conducted using Mix method namely quantitave and qualitative method. Quantitative method was used to determine the basic commodity based on population and institutional variables, then qualitative method was used to analyze the potential development of livestock products. The result showed there were seven regencies that have potential to develop beef cattle commodity businesses, namely Indramayu Regency, Kuningan Regency, Pangandaran Regency, Subang Regency, Tasikmalaya Regency, Sumedang Regency, and Majalengka Regency. Meanwhile, dairy cattle have the potential to be developed in six regencies, namely West Bandung regency, Cimahi Regency, Bandung Regency, Bogor Regency, Kuningan Regency, and Subang Regency. Toward, It is hoped that the business development of beef cattle and dairy cattle can be developed in these areas by empowering livestock groups and utilizing local resources.

Keywords: Base Commodity, UPH, Farmer Institution

\section{PENDAHULUAN}

Usaha bidang peternakan
merupakan salah satu usaha yang
menjanjikan. Permintaan produk
peternakan semakin meningkat seiring

dengan peningkatan jumlah penduduk, perkembangan ekonomi masyarakat, perbaikan tingkat pendidikan, perubahan gaya hidup serta urbanisasi. Menurut Buku Statistik Peternakan dan Keswan 
Ditjen PKH Tahun 2021, menunjukkan bahwa konsumsi daging olahan matang meningkat dari tahun 2017-2020. Tahun 2017 konsumsinya sebesar 18,718 potong/kapita/tahun atau meningkat $75,8 \%$ pada tahun 2020 menjadi 32,9 potong/kapita/tahun. Begitu juga dengan hasil lain dari olahan susu meningkat dari 0,261 ons/kapita/tahun pada tahun 2017 menjadi 1,251 ons/kapita/tahun pada tahun 2021 atau meningkat 3 kali lipat. Peningkatan permintaan produk peternakan ini menjadi peluang bagi masyarakat untuk mengembangkan usaha di bidang peternakan.

Untuk pemenuhan kebutuhan pangan saat ini, Indonesia masih melakukan impor dari luar negeri. Tercatat tahun 2020 Indonesia mengimpor $484.775,4$ ton susu, dan 230.580,4 ton daging (Direktorat Jenderal Peternakan dan Kesehatan Hewan, 2021). Ketahanan pangan akan terwujud jika Indonesia mampu memproduksi kebutuhan pangan dari dalam negeri dengan tetap memperhatikan pemberdayaan peternak rakyat melalui pemanfaatan potensi sumber daya lokal dan didukung oleh penggunaan teknologi, kelembagaan, permodalan dan pemasaran (Kusuma, Diwyanto; Atien, Priyanti; Ismenth, 2005)
Kondisi ini menjadi peluang untuk bisa mendorong peternak rakyat agar bisa berdaya saing dengan mengefisiensikan usahanya, meningkatkan kualitas produk, menjamin kontinuitas supply sesuai dengan permintaan pasar.

Menurut Gunawan et al., (2019), kelembagaan petani dan akses pasar merupakan faktor yang berpengaruh terhadap keberlanjutan usaha. Ketersediaan pasar membuat peternak semakin percaya diri untuk melaksanakan kegiatan usahanya. Menurut hasil SUTAS BPS (2018), rumah tangga usaha subsektor peternakan memberikan kontribusi paling besar terhadap rumah tangga usaha pertanian sebesar 13,5 juta rumah tangga peternak. Dari jumlah tersebut, usaha komoditas ruminansia besar paling banyak dilakukan oleh masyarakat sebesar 4,7 juta rumah tangga peternak (BPS, 2018). Data tersebut menunjukkan peluang usaha pengolahan hasil komoditas ruminansia besar bagi kelompok ternak/gapoktan/koperasi. Menurut Zakaria (2009), melalui pemberdayan kelembagaan petani/ peternak, kegiatan produksi akan lebih efisien sehingga keuntungan usaha, pendapatan, kesejahteraan petani akan meningkat. 
Direktorat Pengolahan dan Pemasaran Hasil Peternakan Ditjen PKH (siupin.pertanian.go.id) di Provinsi Jawa Barat terdapat kurang lebih 118 kelompok ternak/gapoktan/koperasi yang telah melakukan usaha pengolahan hasil peternakan pada komoditas ternak ruminansia besar. Produk olahan yang di hasilkan berupa bakso, abon, dendeng, rendang, susu pasteurisasi, yoghurt, kompos organik, kerajinan kulit, kerupuk susu, permen susu, es krim dan lain-lain. Ini menunjukkan ketersediaan pasar bagi kelompok ternak/Gapoktan/Koperasi sudah terbentuk dan menjadi peluang bagi peternak untuk membentuk kelompok ternak atau gabungan kelompok ternak bahkan koperasi agar bisa mengefisiensikan usahanya. Dengan jumlah populasi ternak ruminansia besar saat ini yang menjadi tantangan adalah bagaimana pengembangan potensi usaha hasil ternak berbasis populasi dan kelembagaan usaha ternak bisa terus ditingkatkan. Tujuan dari penelitian ini adalah untuk mengetahui potensi pengembangan usaha pengolahan hasil peternakan, khususnya ternak ruminansia besar di Provinsi Jawa Barat.

\section{METODE PENELITIAN}

Penelitian dilakukan pada bulan November-Desember 2021 di Provinsi Jawa Barat. Data yang diambil adalah data populasi ternak dan data usaha pengolahan hasil peternakan di Provinsi Jawa Barat. Penelitian dilakukan dengan metode gabungan (mixed method), yaitu metode kuantitatif dan kualitatif. Metode kuantitatif digunakan untuk mengetahui komoditas basis berdasarkan variabel populasi dan kelembagaan, kemudian metode kualitatif digunakan untuk menganalisis pengembangan potensi usaha hasil ternak. Sumber data berupa data sekunder yang diperoleh dari dari Dinas Ketahanan dan Peternakan Provinsi Jawa Barat Tahun 2021 serta Sistem Informasi Unit Pengolahan Hasil Peternakan Indonesia (SI UPIn) yang di buat oleh Direktorat Pengolahan dan Pemasaran Hasil Peterenakan Ditjen PKH Kementerian Pertanian Tahun 2021. Data sekunder adalah data yang tidak secara langsung memberikan data kepada pengumpul data, tetapi melalui orang lain atau melalui dokumen (Sugiyono, 2016). Data sekunder adalah sumber data pelengkap untuk melengkapi sumber data primer.

Teknik pengumpulan data dilakukan melalui studi literatur yang 
terkait dengan penelitian ini. Analisis yang digunakan adalah analisis Location Quotient (LQ) untuk menentukan komoditas unggalan ternak.

Analisis LQ pertama kali diperkenalkan oleh Sargent Florence, seperti yang di kutip oleh Guimarães et al., (2009) bahwa analisis ini digunakan untuk mengukur konsentrasi industri di daerah. Selain itu, hasil dari analisis ini diterapkan untuk memperkirakan kekuatan ekonomi regional dan kegiatan ekspor. Dari pemahaman terhadap ekonomi basis, analisis LQ juga bisa digunakan untuk menentukan komoditas unggulan pertanian seperti usaha ternak, dengan menggunakan dasar perhitungan yang digunakan adalah jumlah populasi (ekor) (Hendayana, 2003).

Komoditas unggulan diperoleh berdasarkan rasio antara populasi komoditas i pada tingkat wilayah terhadap total populasi wilayah dengan populasi komoditas i pada tingkat nasional terhadap total populasi nasional.

Formulasi analisis LQ dituliskan sebagai berikut :

$$
L Q=\frac{p i / p t}{P i / P t}
$$

Keterangan :

\section{$L Q$ : Location Quotient}

pi : Populasi komoditas i pada suatu wilayah $p t$ : Total populasi ternak pada suatu wilayah

$P i$ : Populasi komoditas i pada tingkat nasional

Pt : Total populasi ternak pada tingkat nasional

Hasil Perhitungan dari analisis LQ menghasilkan 3 kriteria, yaitu :

1. LQ $>1:$ Komoditas ternak tersebut adalah komoditas basis, dan memiliki keunggulan komparatif. Hasilnya tidak saja untuk wilayah tersebut tapi bisa diekspor ke wilayah lain.

2. $\mathrm{LQ}=1:$ Komoditas ternak tersebut bukan merupakan komoditas basis. Komoditasnya hanya cukup untuk memenuhi kebutuhan wilayahnya saja.

3. LQ $<1$ : Komoditas ternak tersebut tidak merupakan komoditas basis. Produksi komoditas di wilayahnya belum mencukupi untuk memenuhi kebutuhan wilayahnya sehingga memerlukan pasokan dari wilayah lain.

Perhitungan analisis LQ terhadap komoditas ternak di provinsi Jawa Barat di bagi dua berdasarkan ternak ruminansi dan ternak unggas. Hal ini dilakukan agar tidak terjadi bias pada perhitungan 
jumlah populasi ternak secara keseluruhan.

Analisis berikutnya adalah dengan mengelompokan data dari Sistem Informasi Unit Pengolahan Hasil Peternakan Indonesia berdasarkan komoditas ternak yang dijadikan usaha peternakan oleh kelompok ternak/ gapoktan/koperasi. Selanjutnya hasil dari pengelompokan tersebut disandingkan dengan hasil perhitungan analisis LQ untuk dilakukan analisis deskriptif.

\section{HASIL DAN PEMBAHASAN}

\section{Gambaran Populasi Ternak Ruminansia Besar (Sapi Potong dan Sapi Perah) di Provinsi Jawa Barat}

Populasi sapi potong di provinsi Jawa Barat Tahun 2020 sebesar 392.590 ekor (Ditjen PKH, 2021), atau memberikan kontribusi sebesar 2,3\% terhadap populasi sapi potong nasional. Kantung-kantung ternak tersebar di beberapa kabupaten, yaitu Tasikmalaya, Cianjur, Sumedang, Kuningan, dan Subang (DKPP Provinsi Jawa Barat, 2021). Hasil penelitian menunjukkan bahwa ternak sapi potong dan sapi perah memiliki potensi untuk dikembangkan menjadi kawasan peternakan di Provinsi Jawa Barat dengan berbasis daya dukung lokal (Arief et al., 2015). Meningkatnya ekonomi masyarakat menjadikan Jawa
Barat sebagai salah satu sentra konsumsi daging sapi bersama DKI Jakarta (Ilham, 2009). Hal ini terlihat dari setiap satu RPH di Jawa Barat mampu menangani 2.000 ekor sapi. (Yusdja \& Ilham, 2004).

Berbeda dengan sapi potong, sapi perah di Jawa Barat memberikan kontribusi sebesar $20,9 \%$ terhadap populasi sapi perah nasional atau sekitar 118.434 ekor (Ditjen PKH, 2021). Konsentrasi populasi sapi perah berada di Kabupaten Bandung Barat, Bandung, Garut, Bogor dan Kuningan (DKPP Provinsi Jawa Barat, 2021).

Tabel 1. Populasi Sapi Potong dan Sapi Perah Provinsi Jawa Barat Tahun 2020

\begin{tabular}{clcccc}
\hline & & \multicolumn{4}{c}{ Populasi } \\
\cline { 3 - 6 } No & Kabupaten/Kota & Sapi & $\%$ & Sapi & $\%$ \\
& & Potong & & Perah & \\
\hline 1 & Bogor & 19.964 & 5.09 & 9.054 & 7.64 \\
2 & Sukabumi & 20.618 & 5.25 & 2.967 & 2.51 \\
3 & Cianjur & 43.268 & 11.02 & 2.483 & 2.10 \\
4 & Bandung & 23.779 & 6.06 & 28.670 & 24.21 \\
5 & Garut & 13.368 & 3.41 & 12.368 & 10.44 \\
6 & Tasikmalaya & 56.107 & 14.29 & 2.231 & 1.88 \\
7 & Ciamis & 10.195 & 2.60 & 71 & 0.06 \\
8 & Kuningan & 29.533 & 7.52 & 7.737 & 6.53 \\
9 & Cirebon & 4.785 & 1.22 & 169 & 0.14 \\
10 & Majalengka & 15.073 & 3.84 & 702 & 0.59 \\
11 & Sumedang & 34.915 & 8.89 & 3.703 & 3.13 \\
12 & Indramayu & 11.033 & 2.81 & - & - \\
13 & Subang & 26.784 & 6.82 & 5.721 & 4.83 \\
14 & Purwakarta & 13.558 & 3.45 & 20 & 0.02 \\
15 & Karawang & 6.511 & 1.66 & 8 & 0.01 \\
16 & Bekasi & 22.081 & 5.62 & 54 & 0.05 \\
17 & Bandung Barat & 6.582 & 1.68 & 39.267 & 33.16 \\
18 & Pangandaran & 18.137 & 4.62 & - & - \\
19 & Kota Bogor & 216 & 0.06 & 1.129 & 0.95 \\
20 & Kota Sukabumi & 605 & 0.15 & 93 & 0.08 \\
21 & Kota Bandung & 1.339 & 0.34 & 641 & 0.54 \\
22 & Kota Cirebon & 353 & 0.09 & - & - \\
23 & Kota Bekasi & 6.427 & 1.64 & 69 & 0.06 \\
24 & Kota Depok & 2.526 & 0.64 & 506 & 0.43 \\
25 & Kota Cimahi & 342 & 0.09 & 552 & 0.47 \\
26 & Kota Tasikmalaya & 2.934 & 0.75 & 219 & 0.18 \\
27 & Kota Banjar & 1.557 & 0.40 & - & - \\
\hline Sumber D DKPP Provinsi Jawa & Barat & 2021 &
\end{tabular}

Sumber : DKPP Provinsi Jawa Barat 2021 
Menurut Karuniawati dan Fariyanti, (2013), bahwa Provinsi Jawa Barat cocok untuk dilakukan pengembangan sapi perah karena daerahnya terdapat banyak pegunungan dan dataran tinggi, memiliki hijauan yang cukup untuk kebutuhan pakan, terdapat pabrik pakan, industri pengolahan susu yang relatif maju dan adanya kelembagaan peternak sapi perah yang tergabung dalam GKSI (Gabungan, Koperasi Susu Indonesia).

Komoditas Basis dan Lokasi UPH Ternak Ruminansia Besar di Provini Jawa Barat

\section{Komoditas Basis}

Analisis Location Quotent (LQ) sering digunakan untuk menentukan spesialisasi suatu daerah pada sektor tertentu. Menurut Sengkey et al., (2017), data populasi ternak bisa digunakan untuk menghitung apakah suatu daerah merupakan sektor basis atau sektor non basis. Jika nilai LQ lebih dari 1 (satu) menunjukkan bahwa wilayah tersebut merupakan sektor basis, sedangkan jika nilai LQ kurang dari 1 (satu) menunjukkan bahwa wilayah tersebut bukan merupakan sektor basis. Hasil analisis LQ komoditas sapi potong dan sapi perah dapat dilihat pada Tabel 2 dan 3.
Tabel 2. Hasil Analisis LQ Komoditas Sapi Potong

\begin{tabular}{|c|c|c|}
\hline No & Kabupaten & Nilai LQ \\
\hline 1 & Indramayu & 1.31 \\
\hline 2 & Pangandaran & 1.31 \\
\hline 3 & Kota Banjar & 1.31 \\
\hline 4 & Kota Cirebon & 1.31 \\
\hline 5 & Karawang & 1.31 \\
\hline 6 & Purwakarta & 1.31 \\
\hline 7 & Bekasi & 1.31 \\
\hline 8 & Ciamis & 1.30 \\
\hline 9 & Kota Bekasi & 1.30 \\
\hline 10 & Cirebon & 1.27 \\
\hline 11 & Tasikmalaya & 1.26 \\
\hline 12 & Majalengka & 1.25 \\
\hline 13 & Cianjur & 1.24 \\
\hline 14 & Kota Tasikmalaya & 1.22 \\
\hline 15 & Sumedang & 1.18 \\
\hline 16 & Sukabumi & 1.15 \\
\hline 17 & Kota Sukabumi & 1.14 \\
\hline 18 & Kota Depok & 1.09 \\
\hline 19 & Subang & 1.08 \\
\hline 20 & Kuningan & 1.04 \\
\hline 21 & Bogor & 0.90 \\
\hline 22 & Kota Bandung & 0.89 \\
\hline 23 & Garut & 0.68 \\
\hline 24 & Bandung & 0.59 \\
\hline 25 & Kota Cimahi & 0.50 \\
\hline 26 & Kota Bogor & 0.21 \\
\hline 27 & Bandung Barat & 0.19 \\
\hline
\end{tabular}

Hasil analisis LQ pada Tabel 2 menunjukan bahwa Kabupaten Indramayu memiliki nilai paling besar $(1,31)$, ini menunjukan bahwa perbandingan populasi sapi potong terhadap total populasi ternak ruminansia di Kabupaten Indramayu lebih besar dibandingkan dengan populasi ternak sapi potong terhadap total populasi ternak ruminansia besar di Provinsi Jawa Barat. Kabupaten Bandung Barat memiliki nilai LQ paling rendah $(0,19)$, menunjukan bahwa perbandingan ternak sapi potong terhadap total ternak ruminansia besar di Kabupaten Bandung Barat lebih kecil 
dibandingkan dengan populasi ternak sapi potong terhadap total populasi ternak ruminansia besar di Provinsi Jawa Barat.

Dari 27 wilayah kab/kota di Provinsi Jawa Barat terdapat 20 wilayah kab/kota yang menjadi wilayah basis, diantaranya kabupaten Indramayu, Pangandaran, Kota Banjar, Kota Cirebon, Karawang, Purwakarta, Bekasi, Ciamis, Kota Bekasi, Cirebon, Tasikmalaya, Majalengka, Cianjur, Kota Tasikmalaya, Sumedang, Sukabumi, Kota Sukabumi, Kota Depok, Subang dan Kuningan.

Tabel 3. Hasil Analisis LQ Komoditas Sapi

\begin{tabular}{|c|c|c|}
\hline \multicolumn{2}{|r|}{ Perah } & \multirow[b]{2}{*}{ Nilai LQ } \\
\hline No & Kabupaten & \\
\hline 1 & Bandung Barat & 5.10 \\
\hline 2 & Kota Bogor & 5.00 \\
\hline 3 & Kota Cimahi & 3.68 \\
\hline 4 & Bandung & 3.26 \\
\hline 5 & Garut & 2.86 \\
\hline 6 & Kota Bandung & 1.93 \\
\hline 7 & Bogor & 1.55 \\
\hline 8 & Kuningan & 1.24 \\
\hline 9 & Subang & 1.03 \\
\hline 10 & Kota Depok & 0.98 \\
\hline 11 & Kota Sukabumi & 0.78 \\
\hline 12 & Sukabumi & 0.74 \\
\hline 13 & Sumedang & 0.56 \\
\hline 14 & Kota Tasikmalaya & 0.41 \\
\hline 15 & Cianjur & 0.32 \\
\hline 16 & Majalengka & 0.26 \\
\hline 17 & Tasikmalaya & 0.22 \\
\hline 18 & Cirebon & 0.20 \\
\hline 19 & Kota Bekasi & 0.06 \\
\hline 20 & Ciamis & 0.04 \\
\hline 21 & Bekasi & 0.01 \\
\hline 22 & Purwakarta & 0.01 \\
\hline 23 & Karawang & 0.01 \\
\hline 24 & Indramayu & - \\
\hline 25 & Pangandaran & - \\
\hline 26 & Kota Cirebon & - \\
\hline 27 & Kota Banjar & - \\
\hline
\end{tabular}

kabupaten/kota merupakan wilayah basis sapi perah di Jawa Barat, diantaranya: Bandung Barat, Kota Bogor, Kota Cimahi, Bandung, Garut, Kota Bandung, Bogor, Kuningan, dan Subang.

Tabel 3 menunjukkan bahwa nilai LQ Kabupaten Bandung Barat paling besar $(5,1)$, menunjukkan bahwa perbandingan populasi ternak sapi perah terhadap total populasi ternak ruminansia besar di Kabupaten Bandung Barat lebih besar dibandingkan dengan populasi ternak sapi perah terhadap total populasi ternak ruminansia besar di Provinsi Jawa Barat. Sedangkan Kabupaten Indramayu, Pangandaran, Kota Cirebon, dan Kota Banjar tidak memiliki nilai LQ dikarenakan menurut data dari Dinas Ketahanan Pangan dan Peternakan Provinsi Jawa Barat, di wilayah tersebut tidak tercatat adanya populasi ternak sapi perah.

Pembangunan ekonomi yang mengacu pada sektor unggulan akan berdampak pada percepatan pertumbuhan dan perubahan pada struktur ekonomi. Sektor ini berkembang melalui kegiatan investasi dan menjadi tumpuan kegiatan ekonomi di wilayah tersebut (Hutapea et al., 2020). 


\section{Lokasi UPH Peternakan}

Lokasi Unit Pengolahan Hasil (UPH) Peterakan diperoleh dari Sistem informasi yang dikelola oleh Direktorat Pemasaran dan Pengolahan Hasil Peternakan, Ditjen Peternakan dan Kesehatan Hewan Kementerian Pertanian. Sistem ini dapat diakses melalui URL (Uniform Resource Locators) (siupin.pertanian.go.id). Dari sistem informasi ini kemudian dikelompokan berdasarkan kelompok usaha pengolahan hasil peternakan komoditas sapi potong dan sapi perah. Hasil pengelompokan tersebut dapat dilihat pada Tabel 4 dan 5 .

\begin{tabular}{|c|c|c|}
\hline No & Kabupaten & Jumlah UPH \\
\hline 1 & Indramayu & 16 \\
\hline 2 & Bandung & 9 \\
\hline 3 & Kuningan & 4 \\
\hline 4 & Kota Bandung & 2 \\
\hline 5 & Bandung Barat & 2 \\
\hline 6 & Pangandaran & 2 \\
\hline 7 & Garut & 2 \\
\hline 8 & Subang & 2 \\
\hline 9 & Kota Tasikmalaya & 1 \\
\hline 10 & Cianjur & 1 \\
\hline 11 & Sumedang & 1 \\
\hline 12 & Bogor & 1 \\
\hline 13 & Majalengka & 1 \\
\hline
\end{tabular}

Tabel 4 menunjukkan jumlah UPH Sapi Potong di Jawa Barat sebagian besar terdapat di Kabupaten Indramayu sebanyak 16 unit, Kabupaten Bandung 9 unit, Kuningan 4 unit, Kota Bandung, Bandung Barat, Pangandaran, Garut dan
Subang masing-masing 2 unit. Sisanya Kota Tasikmalaya, Cianjur, Sumedang, Bogor dan Majalengka masing-masing 1 unit.

\begin{tabular}{clc}
\multicolumn{2}{c}{ Tabel 5. } & Jumlah UPH Komoditas Sapi Perah \\
\hline No & \multicolumn{1}{c}{ Kabupaten } & Jumlah UPH \\
\hline 1 & Bandung & 19 \\
2 & Bogor & 12 \\
3 & Bandung Barat & 9 \\
4 & Subang & 7 \\
5 & Sukabumi & 5 \\
6 & Tasikmalaya & 5 \\
7 & Sumedang & 5 \\
8 & Kota Tasikmalaya & 4 \\
9 & Cianjur & 3 \\
10 & Kuningan & 2 \\
11 & Pangandaran & 1 \\
12 & Ciamis & 1 \\
13 & Kota Cimahi & 1 \\
\hline
\end{tabular}

Sedangkan lokasi UPH komoditas ternak sapi perah paling banyak di Kabupaten Bandung sebanyak 19 unit, Bogor 12 unit, Bandung Barat 9 unit, Subang 7 unit, Sukabumi, Tasikmalaya, Sumedang masing-masing 5 unit, Kota Tasikmalaya 4 unit, Cianjur 3 unit, Kuningan 2 unit, dan Pangandaran, Ciamis, Kota Cimahi masing-masing 1 unit.

\section{Pengembangan Potensi Usaha Hasil Peternakan}

Menurut Fu'ad (2015) menyatakan bahwa variabel terbesar yang berpengaruh terhadap keberhasilan usaha adalah biaya lokasi. Lokasi usaha yang berdekatan dengan target pasar memiliki kelebihan dalam hal biaya pengiriman yang lebih hemat. Faktor-faktor yang 
mempengaruhi lokasi usaha antara lain : lingkungan masyarakat, ketersediaan sumber daya alam, tenaga kerja, kedekatan pasar, ketersediaan transportasi, serta lahan (Harding, 1978).

Hasil analisis LQ menunjukkan bahwa wilayah tersebut memiliki keunggulan komparatif terhadap komoditas tersebut, menjadikan wilayahnya sebagai sumber bahan baku bagi usaha pengolahan hasil peternakan. Keberadaan lokasi UPH saat ini menunjukkan bahwa ketersediaan pasar produk sudah terbentuk. Menjadi sebuah keuntungan besar dan merupakan potensi bagi pengembangan usaha ketika lokasi sumber bahan baku dan pasar berada pada satu wilayah. Dari Tabel 2 dan 4 dapat ditentukan bahwa Kabupaten Indramayu, Kuningan, Pangandaran, Subang, Kota Tasikmalaya, Sumedang, dan Majalengka merupakan wilayah yang berpotensi untuk dikembangan usaha pengolahan hasil peternakan dari komoditas sapi potong.

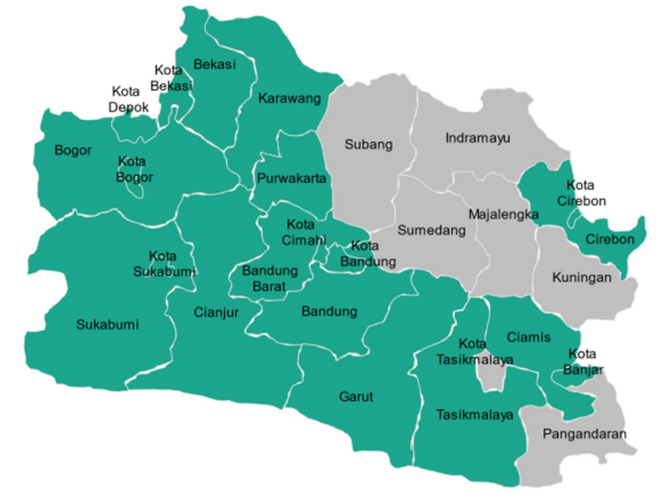

Gambar 1. Peta Pengembangan Potensi Sapi Potong
Dari Tabel 3 dan 5 dapat ditentukan wilayah yang berpotensi untuk pengembangan usaha pengolahan hasil peternakan dengan komoditas ternak sapi perah adalah Kabupaten Bandung Barat, Kota Cimahi, Bandung, Bogor, Kuningan, dan Subang. Sejalan dengan model penggunaan lahan Von Thunen yang dikutip oleh Roos et al., (2018), bahwa peternakan sapi perah dan pertanian intensif harus berada dekat dengan pusat kota, karena susu, sayursayuran dan buah-buahan adalah produk yang harus segera dipasarkan. Gambar 2 menunjukkan bahwa Kabupaten Bogor sebagai supply kebutuhan susu untuk wilayah DKI Jakarta. Sedangkan wilayah Subang, Kota Cimahi, Bandung Barat, dan Bandung mensupply kebutuhan untuk kota Bandung. Kabupaten Kuningan diuntungkan karena lokasi geografis yang cocok untuk peternakan sapi perah dan mencukupi kebutuhan sebagian kecil kebutuhan wilayahnya.

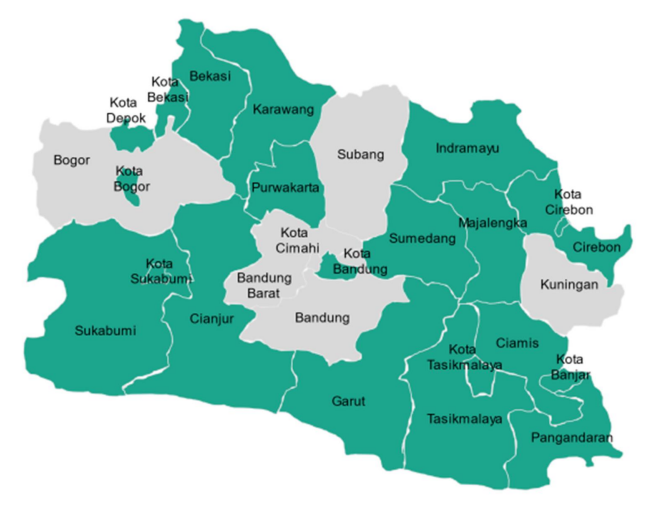

Gambar 2. Peta Pengembangan Potensi Sapi Perah 
Selain karena faktor lokasi usaha, pengembangan usaha kelompok juga ditentukan faktor kelembagaan. Menurut Zulu et al., (2018) Penataan kelembagaan peternak sebagai strategi paling disukai untuk mengurangi kematian ternak, memantau, memfasilitasi perumusan aturan dan penyelesaian konflik kelompok. Kebijakan dan strategi yang berkembang dan secara efektif menghubungkan peternak rakyat ke pasar yang andal dan harga yang kompetitif.

Wahyuni, (2003), menyatakan bahwa dalam jumlah anggota, struktur organisasi, aset kelompok, pemilikan lahan, kredibilitas anggota dan kelembagaan kelompok mempengaruhi kinerja kelompok tani dalam mengembangakan usahanya.

Selain itu, Sulistyati et al., (2013) dalam penelitiannya menyatakan bahwa usaha peternakan sapi perah masih menarik minat masyarakat dan perlu bantuan sarana dan prasarana dalam upaya meningkatkan kuantitas dan kualitas produksi susunya.

\section{KESIMPULAN DAN SARAN}

\section{Kesimpulan}

Berdasarkan hasil pembahasan di atas dapat disimpulkan bahwa wilayah pengembangan usaha pengolahan hasil peternakan komoditas sapi potong masih berpotensi di wilayah kabupaten Kabupaten Indramayu, Kuningan, Pangandaran, Subang, Kota Tasikmalaya, Sumedang, dan Majalengka. Sedangkan komoditas sapi perah berpotensi dikembangkan di wilayah Kabupaten Bandung Barat, Kota Cimahi, Bandung, Bogor, Kuningan, dan Subang.

\section{Saran}

Harapannya kedepan pengembangan usaha hasil peternakan komoditas sapi potong dan sapi perah bisa dikembangkan di wilayah-wilayah tersebut dengan pemberdayaan kelompok ternak dan memanfaatkan sumber daya daya lokal.

\section{DAFTAR PUSTAKA}

Arief, H., Khaerani, L., \& Zamhir Islami, R. (2015). Peta Potensi Kawasan Peterakan Berbasis Daya Dukung Lokal Di Jawa Barat. 1015-1026.

BPS. (2018). Hasil Survei Pertanian Antar Sensus (SUTAS) 2018 The Result Of Inter-Census Agricultural Survey.

Dinas Ketahanan Pangan dan Peternakan Provinsi Jawa Barat. (2021). Statistik Ketahanan Pangan dan Peternakan Tahun 2021.

Direktorat Jenderal Peternakan dan Kesehatan Hewan. (2021). Statistik Peternakan dan Kesehatan Hewan Livestock and Animal Health Statistics 2021.

Fu'ad, E. N. (2015). Pengaruh Pemilihan 
Lokasi Terhadap Kesuksesan Usaha Berskala Mikro/Kecil Di Komplek Shopping Centre Jepara. Media Ekonomi Dan Manajemen, 30(1), 56-67.

Guimarães, P., Figueiredo, O., \& Woodward, D. (2009). Dartboard tests for the location quotient. Regional Science and Urban Economics, 39(3), 360-364. https://doi.org/10.1016/j.regsciurbe co.2008.12.003

Gunawan, G., Hubeis, A. V. S., Fatchiya, A., \& Susanto, D. (2019). Dukungan Penyuluhan dan Lingkungan Ekternal terhadap Adopsi Inovasi dan Keberlanjutan Usaha Pertanian Padi Organik. Agriekonomika, $\quad 8(1), \quad 70$. https://doi.org/10.21107/agriekono mika.v8i1.4951

Harding, H. A. (1978). Manajemen Produksi. Balai AKsara.

Hendayana, R. (2003). Aplikasi Metode Location Quotient (LQ) dalam Penentuan Komoditas Unggulan Nasional. Jurnal Informatika Pertanian, 12(Desember 2003), 121.

http://www.litbang.pertanian.go.id/ warta-ip/pdf-file/rahmadi-12.pdf

Hutapea, A., Koleangan, R. A. M., Rorong, I. P. F., Pembangunan, J. E., Ekonomi, F., \& Ratulangi, U. S. (2020). Analisis Sektor Basis Dan Non Basis Serta Daya Saing Ekonomi Dalam Peningkatan Pertumbuhan Ekonomi Kota Medan. Jurnal Berkala Ilmiah Efisiensi, 20(03), 1-11.

Ilham, N. (2009). Daging Sapi Nasional: Policy on National Beef Price Control. Jurnal Analisis Kebijakan Pertanian, 7(3), 211-221.

Karuniawati, R., \& Fariyanti, A. (2013). Faktor-Faktor Yang Mempengaruhi Produksi Susu Sapi Perah Di Kecamatan Megamendung
Kabupaten Bogor Provinsi Jawa Barat. Forum Agribisnis : Agribusiness Forum, 3(1), 73-86. https://doi.org/10.29244/fagb.3.1.7 3-86

Kusuma, Diwyanto; Atien, Priyanti; Ismenth, I. (2005). Prospek dan Arah Pengembangan Komoditas Peternakan. Wartazoa, 1, 11-25.

Roos, A., Eggers, J., Mark-Herbert, C., \& Lindhagen, A. (2018). Using von Thünen rings and service-dominant logic in balancing forest ecosystem services. Land Use Policy, 79(September), 622-632. https://doi.org/10.1016/j.landusepol .2018 .08 .046

Sengkey, N. M., Salendu, A. H. ., Wantasen, E. ., \& Waleleng, P. O. . (2017). Potensi Pengembangan Ternak Sapi Potong Di Kecamatan Tompaso Barat. Zootec, 37(2), 350. https://doi.org/10.35792/zot.37.2.20 17.16155

Sugiyono, S. (2016). Metode Penelitian Kuantitatif, Kualitatif dan $R \& D$. Alfabeta.

Sulistyati, M., Hermawan, \& Fitriani, A. (2013). Potensi Usaha Peternakan Sapi Perah Rakyat dalam Menghadapi Pasar Global. Jurnal Ilmu Ternak, 13(1), 17-23. http://jurnal.unpad.ac.id/jurnalilmut ernak/article/view/5116

Wahyuni, S. (2003). Kinerja kelompok tani dalam sistem usaha tani padi dan metode pemberdayaannya. 70 , $1-8$.

Yusdja, Y., \& Ilham, N. (2004). Tinjauan Kebijakan Pengembangan Agribisnis Sapi Potong. 2, No 2(70), 183-203.

Zakaria, W. A. (2009). Penguatan kelembagaan kelompok tani kunci kesejahteraan petani. Prosiding Nasional Dinamika Pembangunan Pertaniaan Dan Pedesaan, 294 315. 
Zulu, L. C., Adams, E. A., Chikowo, R., \& Snapp, S. (2018). The role of community-based livestock management institutions in the adoption and scaling up of pigeon peas in Malawi. Food Policy, 79(June), 141-155. https://doi.org/10.1016/j.foodpol.20 18.06.007 